\title{
O PRINCÍPIO DA LEGALIDADE E A UTILIZAÇÃO INDEVIDA DA PARCERIA PÚBLICA COM O SETOR PRIVADO
}

\section{FABIANA CARICATI}

Advogada. Mestranda do Programa de Pós-Graduação Strictu Sensu em Direito Empresarial e Cidadania no Centro Universitário Curitiba - Unicuritiba, Paraná. email: fabiana@caricati.adv.br.

CLAYTON REIS

Professor Orientador. Doutor em Direito pela Universidade Federal do Paraná. Mestre em Direito pela Universidade Federal do Paraná. Bacharel em Direito pela Faculdade de Direito de Curitiba. Magistrado em Segundo Grau, aposentado, do TJPR. Professor na Escola da Magistratura do Paraná e pertence ao Corpo Docente Permanente do Programa de Mestrado em Direito Empresarial e Cidadania do UNICURITIBA. email: claytonreis43@gmail.com

\section{OBJETIVOS}

A promulgação da Constituição de 1988 e a consequente redemocratização do país representou importante fortalecimento e expansão ao Poder Judiciário, na medida em que aumentou a demanda por justiça na sociedade brasileira.

Sem olvidar o clássico conceito da Separação dos Poderes, proposto pelo Barão de Montesquieu e ensinado pelo Professor Jorge Miranda, ao fazer a divisão tricotômica das funções do Estado em função política, administrativa e jurisdicional, um novo papel foi assumido pelo Poder Judiciário, pois não havia espaço para sua inércia quando chamado a prestar a tutela jurisdicional, frente aos descasos cometidos pelos Poderes Legislativo e Executivo (MIRANDA, 2015, p. 344).

Verificou-se um protagonismo cada vez maior do Poder Judiciário, inclusive sendo a ele submetidas questões centrais quanto à forma da organização política, 


\section{Personalidade Acadêmica Homenageada:}

Florisbal de Souza Del'Olmo (Professor Convidado - UNICURITIBA)

distribuição de poderes, competências entre os poderes, moralidade administrativa, efetiva prestação de serviços públicos e a autonomia privada.

A presente pesquisa constatou a intervenção do Poder Judiciário nos outros poderes, visando a garantia e eficiência do Estado Democrático de Direito, forçando o Poder Executivo a adotar medidas que possibilitassem a prestação dos vários serviços públicos garantidos pela Constituição Federal.

Em sequência, este estudo identificou institutos criados para este propósito, dentre eles a figura das parcerias públicas com o setor privado, como forma de supostamente desburocratizar, facilitar a disponibilização dos serviços públicos à população e dar apoio às entidades públicas.

As parcerias entre os setores público e privado, quando observada a legalidade, são fundamentais para garantir a viabilização de políticas públicas, principalmente em razão da escassez de recursos públicos destinados a suprir todas as demandas sociais existentes no Brasil. Os desafios sociais para a erradição da pobreza no país ainda são imensos e as necessidades básicas nas áreas de infraestrutura são gigantescas. Desta forma, os acordos bilaterais entre a iniciativa privada e o Poder Público podem viabilizar investimentos economicamente rentáveis aos parceiros privados e politicamente estratégicos para os Estados (CANEN, 2003, p.8).

Contudo, verificou-se, também, que diante da demanda urgente e da ineficiência dos Poderes Legislativo e Executivo, a Administração Público passou a firmar contratos e parcerias ao arrepio da legalidade, criando figuras que não estão positivadas no direito brasileiro, como é o caso da cooperativa prestadora de serviço público, ou firmando contratos sem a observância dos requisitos legais para fugir do regime jurídico do Direito Público, como é o caso dos convênios, que não são tidos como contratos administrativos, mas na prática se equivalem.

A partir deste ponto, verificou-se a necessidade de pesquisar a figura de alguns institutos de apoio às entidades públicas e suas características. Com a análise da legislação aplicável à matéria e do fluxo de pensamento emergente no país, investigou-se a observância do Princípio da Legalidade para a instituição e utilização de algumas parcerias públicas com o setor privado. 


\section{Personalidade Acadêmica Homenageada:}

\section{Florisbal de Souza Del'Olmo (Professor Convidado - UNICURITIBA)}

\section{METODOLOGIA}

Para as investigações de caráter dedutivo, serviram de fonte de pesquisa a análise bibliográfica e a coleta de dados em trabalhos elaborados em programas de pós-graduação strictu sensu, os quais retratam a doutrina difundida em relação ao princípio da legalidade.

\section{RESULTADOS}

Dentre os três sistemas, o jurisdicional é o mais importante e se realiza com base na garantia do acesso ao Judiciário. A justiciabilidade do ato, como ensina José Afonso da Silva, é a possibilidade de submissão dos atos administrativos ao controle jurisdicional, para que o juiz declare sua conformidade ou não à lei ou o anule (SILVA, 2008, p.428). Da mesma forma, serve o Poder Judiciário para compelir a Administração Pública e praticar atos prescritos em lei e garantir direitos individuais e sociais prescritos na Constituição Federal.

A crise estatal paralisou a prática de inúmeros serviços públicos garantidos pela Constituição Federal aos cidadãos, como o fornecimento gratuito de medicamentos, como também tornou ineficiente e deficitária a prestação de vários outros serviços públicos, como a assistência médica e educacional.

Frente a condição estatal insuficiente para deter o monopólio de produção, a ineficiência para concretização dos direitos e garantias constitucionais e a ineficácia em pacificação dos conflitos, o Judiciário foi acionado para se pronunciar sobre vários aspectos das políticas públicas, compelindo o poder Executivo a adotar medidas para a satisfação de direitos.

Neste contexto, a Administração Pública passou a adotar programas de contratação do setor privado para apoio das entidades estatais na prestação de serviços públicos. Da mesma forma, a iniciativa privada viu uma ótima oportunidade de negócio a criação de instituições por particulares para colaborar com órgãos da Administração, criadas exclusivamente com esse objetivo. 


\section{Personalidade Acadêmica Homenageada:}

Florisbal de Souza Del'Olmo (Professor Convidado - UNICURITIBA)

$\mathrm{Na}$ realidade desta demanda e visando fugir do regime publicístico é que surgiram várias organizações ao arrepio da legalidade, com práticas infratoras que possibilitaram a aplicação de recursos orçamentários duas vezes sobre uma mesma finalidade, a aplicação de objetivos escusos e fraudulentos para complementação financeira por via oblíqua, a compra e estocagem de produtos longe dos controles oficiais, embora às custas de verba pública e a burla aos objetivos institucionais originalmente de sua criação.

O objetivo desta formatação é instituir a parceria entre o poder público e uma organização não governamental qualificada pelo poder público, sob certas condições, para prestar atividade de interesse público mediante variadas formas de fomento pelo Estado, atuando na área dos serviços públicos chamados não exclusivos do Estado, como os serviços sociais, a saúde, a educação, a cultura, dentre outros (DI PIETRO, 2008, p.249).

Foram criadas também as fundações de apoio a entidades públicas e cooperativas prestadoras de serviços públicos, a par da legalidade e dos princípios constitucionais que regem a gestão e proteção do patrimônio público (DI PIETRO, 2008, p.279).

Neste sentido é que foi possível constatar que a própria Administração Pública passou a utilizar indevidamente a parceria com o setor privado como forma de fugir ao regime jurídico publicístico, o qual é centralizado, burocrático e vinculado à prestação de contas.

\section{CONCLUSÃO}

O entusiasmo pela privatização não pode afrontar o princípio da legalidade, porque sem este não se pode falar em Estado de Direito.

No Brasil, não se tem uma jurisdição administrativa com função criadora do direito, logo, no direito administrativo, caso a Administração queira criar figuras contratuais novas, terá que procurar seu fundamento no direito positivo. 


\section{Personalidade Acadêmica Homenageada:}

Florisbal de Souza Del'Olmo (Professor Convidado - UNICURITIBA)

Também não é possível ignorar o regime jurídico de direito público, sem que se promovam alterações legislativas para esta finalidade.

O regime jurídico administrativo a que se submete a Administração implica a outorga de prerrogativas e privilégios de que não dispõe o particular, mas também impõe restrições a que o particular não se submete.

A Constituição Federal de 1988 exagerou nos formalismos impostos à Administração Pública, em especial à Administração indireta que recebeu tratamento rigoroso praticamente igual ao da Administração direita, por isso que a privatização é vista como uma forma de fugir deste regime de direito público, contudo, isso vem sendo feito de forma a atropelar o direito positivo, ao invés de procurar flexibilizar os meios de atuação da Administração Pública, pela alteração dos dispositivos legais e constitucionais que a emperram.

Não há dúvidas de que tal conduta coloca em risco o princípio da legalidade, de forma perigosa quando se afirma que as decisões judiciais que determinam a observância da legalidade "atrapalham" a tão almejada reforma do Estado.

Sob o pretexto de ineficiência da Administração Pública, busca-se mecanismos privados de atuação. De qualquer forma, o que se verifica inaceitável é a perpetuação e a oficialização de um regime paralelo ao direito positivo, muitas vezes usado para ludibriar os controles jurídicos e orçamentários próprios do Direito Público.

Por outro lado, não se pode olvidar que o princípio da legalidade está acompanhado de uma séria de outros direitos, valores e garantias constitucionais que a eficácia administrativa não pode desconhecer. A igualdade perante a lei, a liberdade de concorrência, a segurança jurídica, a ampla defesa, o devido processo legal, o controle efetivo dos gastos públicos, dentre outros, são pilares fundamentais do ordenamento jurídico da administração e que condicionam ou limitam o alcance do princípio da eficácia em garantir simultaneamente os interesses gerais e os direitos e interesses individuais.

No tema parceria, encontram-se no direito brasileiro inúmeros exemplos de situações que são frontalmente ilegais ou, pelo menos, estão em zona fronteiriça 
Personalidade Acadêmica Homenageada:

Florisbal de Souza Del'Olmo (Professor Convidado - UNICURITIBA)

com a ilegalidade e a imoralidade administrativa, sempre em nome da almejada eficiência.

Tais situações devem ser fiscalizadas e cerceadas, quando contrárias ao Direito, preservando-se o princípio da legalidade. Mudanças que se entendem necessárias deverão ser feitas por meio de alteração no direito positivo, sem criação de institutos paralelos ao ordenamento jurídico.

De toda sorte, a utilização indevida de parcerias com o setor privado e seu funcionamento ostensivo e irregular junto à Administração, com a tolerância de seus órgãos de controle, demonstra a necessidade de revisão do regime jurídico administrativo estabelecido no direito brasileiro.

\section{REFERÊNCIAS}

BARBOZA, Estefânia Maria de Queiroz. Precedentes Judiciais e Segurança Jurídica: Fundamentos e Possibilidades para a Jurisdição Constitucional Brasileira. São Paulo: Saraiva, 2014.

BONAVIDES, Paulo. Curso de Direito Constitucional. São Paulo: Malheiros Editora, 2005.

CASIMIRO, Ligia Maria Silva Melo. Administração Pública e Planejamento no Estado Brasileiro: Qual a contribuição a ser feita pelo Direito Administrativo? In: Revista Jurídica Unicuritiba, Curitiba, v.4, n.45, p.56-79, 2016.

DI PIETRO, Maria Sylvia Zanella. Parcerias na Administração Pública: concessão, permissão, franquia, terceirização e outras formas. São Paulo: Atlas, 2008.

JUSTEN FILHO, Marçal. Curso de Direito Administrativo. São Paulo: Revista dos Tribunais, 2010.

MELLO, Celso Antônio Bandeira. Curso de Direito Administrativo. São Paulo: Editora Malheiros, 2015.

MEIRELLES, Hely Lopes. Direito Administrativo Brasileiro. São Paulo: Malheiros, 1997. 